\title{
PLACE OF CERVICAL COLLAR IN EMERGENCY MEDICINE
}

\author{
Ruslan Yakubtsevich ${ }^{1}$, Dominika Dunder ${ }^{2}$, Kacper Kranc ${ }^{2}$, \\ Michal Pruc ${ }^{2}$, Adam Pastucha ${ }^{2}$, Aleksandra Koldyj ${ }^{2}$ \\ ${ }^{1}$ Department of Anesthesiology and Intensive Care Grodno State Medical University, Grodno, Belarus \\ ${ }^{2}$ Lazarski University, Warsaw, Poland
}

Disaster Emerg Med J 2018; 3(3): 108-109

\section{Dear Sir,}

We have read the article by Ladny et al. titled „Assessment of the cervical collar application impact on the conditions of intubation and the feelings of patients - pilot study" [1] with great interest. In this article, the main concern raised by the authors is - the use of cervical collar among patients with suspected cervical spine injuries in the outpatient settings. Until recently, the use of cervical collar was a golden standard during emergencies for trauma patients as well as the use of an orthopedic board $[2,3]$.

However, due to the numerous articles, including the article by Bledsoe, which was published in the Journal of Emergency Medical Services [4], the use of a cervical collar is currently being questioned. Bledsoe emphasizes several reasons why the routine use of cervical collar should be limited [4]. The first is the risk of aggravating an injury due to incorrect use of a cervical collar by untrained personnel. The application of a cervical collar should be performed after previous training and in accordance with the manufacturer's instructions (Fig. 1). The second obstacle is the possibility of exacerbating pain which can be caused by excessive pressure of the collar on the mastoid processes. Another hindrance is the reduction of the effectiveness of endotracheal intubation, in case of wearing the cervical collar, which reduces
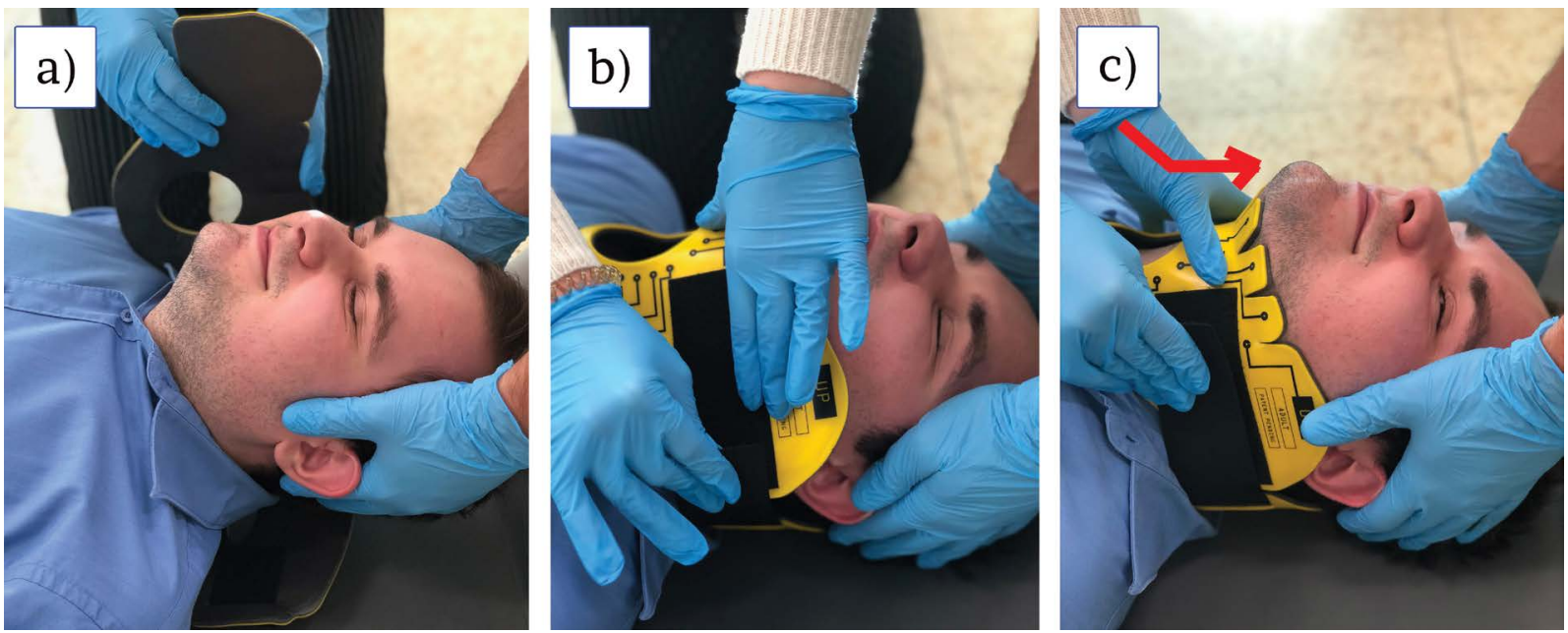

FIGURE 1. Correct application of cervical collar: a) Slide the back of the collar, with the elliptic hole, behind the patient's neck. Continue pushing beneath the patient until you can reach it on the opposite side; b) Wrap the front side around the lower jaw, aligning the oval hole under the chin. Secure the collar tightly around the patient's neck using the Velcro strap; c) Push the small wings against the chin and check that they are in a supportive position. Adjust the collar into a position that immobilizes the neck of the patient and readjust the Velcro strap if necessary. 


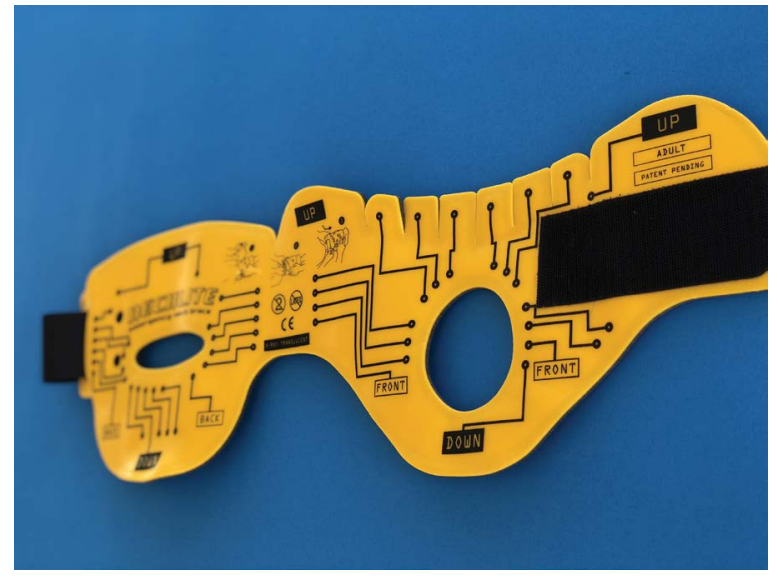

FIGURE 2. The NECKLITE emergency neck brace.

the extension of the oral cavity opening. The fourth and the most crucial complication that can be caused by the cervical collar is the pressure on the external jugular veins that may lead to elevated intracranial pressure, which is already increased in patients suffering from craniocerebral trauma and can expose them to life-threatening situations. Moreover, Hoffman et al. [5] indicate that conscious patients with normal verbal-logic speech have a low probability of experiencing serious complication of the cervical spine.

However, according to research carried out by Ladny et al. there is an alternative to the regular cervical collars, in the form of NECKLITE emergency neck brace (FLAMOR SL, San Pietro Mosezzo, Italy; Fig. 2). The collar is an innovative solution, thanks to its construction it provides a moldable fit to the individual patient and thus stabilization of the cervical spine is well-defined while reducing the pain. Ladny et al. indicated that the extent of the oral cavity opening was varied in three cases: without a collar, with AMBU collar, and with NECKLITE collar. Nonetheless, during the measurement, they detected only a minimal change in the degree of the dilation between collar-free and NECKLITE.

In another research, Szarpak et al. [6] indicated that the sheath thickness of the median optic nerve during the follow-up was 3.6 (3.58-3.95) mm, while 10 minutes after immobilizing the cervical spine using a NECKLITE collar was 3.75 (3.7-4.2) mm, and in the case of stabilizing the spine using a Patriot collar - 4.6 (IQR: 4.35-4.9) mm. In terms of physiology and pathophysiology, emergency procedures with patients suffering from craniocerebral injuries include actions that aim to prevent an increase of intracranial pressure, however, as research by Szarpak et al. [6] as well as Maissan et al. [7] shows that use of standard cervical collars may cause a significant elevation of intracranial pressure.

In the case of patients with craniocerebral injuries, there is a tendency for increased intracranial pressure, which in critical situations may lead to brainstem herniation through the foramen magnum and eventually patient's death.

To sum up, regarding patient protection, further research is necessary to verify the results that were obtained in the studies mentioned above.

\section{REFERENCES:}

1. Ladny M, Smereka J, Szarpak L, et al. Assessment of the cervical collar application impact on the conditions of intubation and the feelings of patients — pilot study. Disaster Emerg Med J . 2018; 3(1): 1-4, doi: 10.5603/DEMJ.2018.0001.

2. WölfI CG, Gliwitzky B, Wentzensen A. Standardised primary care of multiple trauma patients. Prehospital Trauma Life Support und Advanced Trauma Life Support. Unfallchirurg. 2009; 112(10): 846-853, doi: 10.1007/s00113-009-1685-z, indexed in Pubmed: 19756451.

3. Wiles MD. ATLS: Archaic Trauma Life Support? Anaesthesia. 2015; 70(8): 893-897, doi: 10.1111/anae.13166, indexed in Pubmed: 26152249.

4. Bledsoe B. Why EMS should limit the use of rigid cervical collars. JEMS. https://www.jems.com/articles/print/volume-40/issue-2 (20.11.2018).

5. Hoffman JR, Wolfson AB, Todd K, et al. Selective cervical spine radiography in blunt trauma: methodology of the National Emergency X-Radiography Utilization Study (NEXUS). Ann Emerg Med. 1998; 32(4): 461-469, indexed in Pubmed: 9774931.

6. Szarpak L, Ladny M, Pyda S, et al. Comparison of two cervical collars on the intracranial pressure measured indirectly based on the thickness of the optic nerve sheath. Preliminary data. Post N Med . 2018; XXXI(2): 68-71, doi: 10.25121/PNM.2018.31.2.68.

7. Maissan IM, Ketelaars $R$, Vlottes $B$, et al. Increase in intracranial pressure by application of a rigid cervical collar: a pilot study in healthy volunteers. Eur J Emerg Med. 2018; 25(6): e24-e28, doi: 10.1097/ MEJ.0000000000000490, indexed in Pubmed: 28727580. 